\title{
Relógio Solar: Construção do SABer em física APlicada ÀS EDIFICAÇÕES COM EFEITO EXTENSIONISTA
}

\section{Sundials: building knowledge in architectural physics with an university outreach effect}

\author{
Aloísio Leoni Schmid ${ }^{*}$ \\ Wânia Cruz do Nascimento* \\ Caroline Barp Zanchet Machado
}

\begin{abstract}
RESUMO
Este artigo relata a concepção e realização de nove relógios solares em pátios de escolas de ensino fundamental em Curitiba. Trata-se de um projeto realizado no âmbito da disciplina de Conforto Ambiental no curso de Arquitetura e Urbanismo e ainda no estágio de docência de duas mestrandas em Construção Civil. O modelo utilizado é de um relógio solar interativo, em que cada pessoa realiza a leitura das horas a partir da sombra projetada pelo próprio corpo. O intuito principal é a fixação de conhecimentos de geometria solar pelos estudantes de arquitetura. Observou-se em todas as situações um razoável envolvimento destes estudantes, que se apropriaram da responsabilidade executiva e até mesmo pedagógica diante da comunidade das escolas. Desenvolveu-se assim uma atividade prática, eficiente, de efeito extensionista.
\end{abstract}

Palavras-chave: Física das edificações; conforto ambiental; relógio solar; eficiência energética; projeto de arquitetura.

\begin{abstract}
This article is on the conception, implementation and follow-up of nine sundials built in public primary schools in Curitiba within the course Indoor Comfort, career Architecture and City Planning, and within the scope of a teaching internship of two M.Sc. candidates in Civil Construction. An interactive sundial was conceived. The user has to use the own body to cast a shadow and read the time on the ground. The main purpose is to serve as an exercise on solar geometry for architectural students. A high level of engagement was observed by the students, who carried the executive responsibility and even the pedagogic responsibility towards the school communities. A practical activity of both pedagogic value and outreach effectiveness was developed.
\end{abstract}

Keywords: Building physics; indoor comfort; sundial; energy efficiency; architectural design.

\section{RESUMEN}

Este artículo trata de el concepto, la implementación y el seguimiento de nueve relojes solares construidos en escuelas primarias públicas en Curitiba dentro de la disciplina Fisica aplicada a las edificaciones, en la carrera de arquitectura. El deseño adoptado es tal que una persona tiene que parar de modo a proyectar su sombra sobre un mostrador e leer las horas a partir de su sombra. El propósito principal es servir como ejercicio en la geometría solar para los estudiantes de arquitectura. Los estudiantes mostraran un alto nivel de compromiso

Prof. Dr. UFPR, Departamento de Arquitetura e Urbanismo e Programa de Pós-Graduação em Construção Civil - PPGCC, Caixa Postal 19011 - DAU, 81.531-990 - Curitiba - PR, isso@ufpr.br

** Arquitetas e Urbanistas, Mestres em Construção Civil, egressas do PPGCC - UFPR 
e asumieran responsabilidad ejecutiva e también pedagógica. Un alto nivel de compromiso fue logrado contrato fue observado por los estudiantes, que llevaron la responsabilidad ejecutiva e incluso la responsabilidad pedagógica hacia las comunidades de la escuela. Una actividad práctica del valor pedagógico y excede eficacia fue convertida.

\section{Introdução}

Na disciplina de Física Aplicada às Edificações, ainda com relevância para as disciplinas de Construção Civil e Projeto de Arquitetura, é de importância fundamental o conhecimento da geometria da insolação. Ela abrange os movimentos relativos entre o sol e a terra, que têm relação direta com o desempenho energético de edifícios e o conforto térmico dos usuários, e mais ainda: pode vir a influenciar toda uma proposta de zoneamento urbano e seu detalhamento em esquemas de arruamento $e$ definição de gabaritos.

Em especial em época de conscientização a respeito de mudanças climáticas, espera-se que as edificações sejam concebidas $e$ detalhadas de modo a aproveitar as condições naturais em favor do conforto ambiental e da adequação funcional do ambiente construído, resultando em edificações energeticamente eficientes e mais alinhadas com o ideal de sustentabilidade. Uma aplicação direta deste conhecimento se dá no traçado de máscaras de sombreamento, um método gráfico muito eficiente para o projeto exato de aberturas e de sua proteção solar, seja ela na forma de marquises, brise-soleil, toldos ou dos próprios pilares e vigas da estrutura do edifício, concebida de modo a criar controle solar.

A geometria da insolação é um conhecimento cuja transmissão não pode se limitar à mera exposição, uma vez que requer o exercício do raciocínio espacial utilizando relações esféricas e, ao mesmo tempo, aplicado em realidades geralmente cartesianas (os edifícios). Desenhos em vistas, perspectivas, simulações no computador, modelos reduzidos com globos terrestres e lâmpadas, simuladores solares do tipo heliodon para observação de maquetes, sistemas de software de projeto por computador e a observação direta são algumas técnicas que auxiliam no aprendizado.

Uma variação da observação direta, empregada com êxito pelos autores, consistiu em promover um concurso de fotografias do nascer do sol ou do pôr do sol num dos equinócios. Os estudantes recebiam o desafio de produzir fotografias associadas a referências urbanas que indicassem a direção Leste/ Oeste. Assim, estariam fixando o conhecimento de que, nos equinócios, o sol nasce exatamente a Leste e se põe a Oeste - em qualquer lugar do mundo.

Outra forma de apoio à observação direta é encontrada no uso de relógios solares. É o assunto deste artigo. O problema de interesse em ensino de engenharia e arquitetura pode ser formulado na seguinte questão: "como melhorar o aprendizado da geometria solar por meio do uso de relógios solares?"

A hipótese considerada é que um melhor entendimento é esperado se os estudantes tiverem de construir os próprios relógios; ainda, acrescenta-se relevância à atividade se ela transcender o caráter de formalização de uma etapa, mas se for inserida num contexto de extensão universitária. Ao perceber a importância social, assumindo a responsabilidade perante a comunidade beneficiada, os estudantes encarariam com mais naturalidade a necessidade de compreender a geometria solar.

O objetivo deste trabalho é verificar a eficácia da tarefa de construção de relógios solares para uso da comunidade - no caso, escolas públicas de ensino fundamental - como apoio ao aprendizado de orientação solar por estu- 
dantes de arquitetura. Ressalte-se que semelhante projeto poderia ser igualmente desenvolvido com estudantes de engenharia civil, uma vez que o problema de pesquisa se lhes aplica com igual relevância.

O método adotado é a pesquisa-ação na própria aula.

O projeto tem sua justificativa, inicialmente, na necessidade de fixação dos conhecimentos de orientação solar, pelos estudantes de conforto ambiental, disciplina comum nos cursos de Arquitetura e Urbanismo, mas também Engenharia.

Ainda, ressalta-se a necessidade de se disseminar, junto à população, a noção e a prática da construção adequada ao clima e à região. Isto inclui como conhecimento fundamental a orientação solar. Espera-se que ao iniciar a disseminação pelas escolas o efeito social possa ser maximizado, atingindo não só os alunos como os professores das escolas. A observação da natureza é uma habilidade que pode ser ensinada; é esta a opinião do físico Fritjof Capra, que propôs o termo "alfabetização ecológica". Aprender a ver a realidade - por vezes, já seria muito ver a própria cidade - como na figura 1 que mostra um relógio solar que está a 150 anos numa fachada defronte à catedral de Curitiba e é desconhecido de muitos estudantes universitários.

Os dois propósitos somente existem de forma concomitante: ao assumirem com a escola a tarefa da construção de um relógio solar, os estudantes de arquitetura criam um compromisso consigo mesmos de aprofundar conhecimentos referentes à orientação solar.

FIGURA 1 - RELÓGIO SOLAR

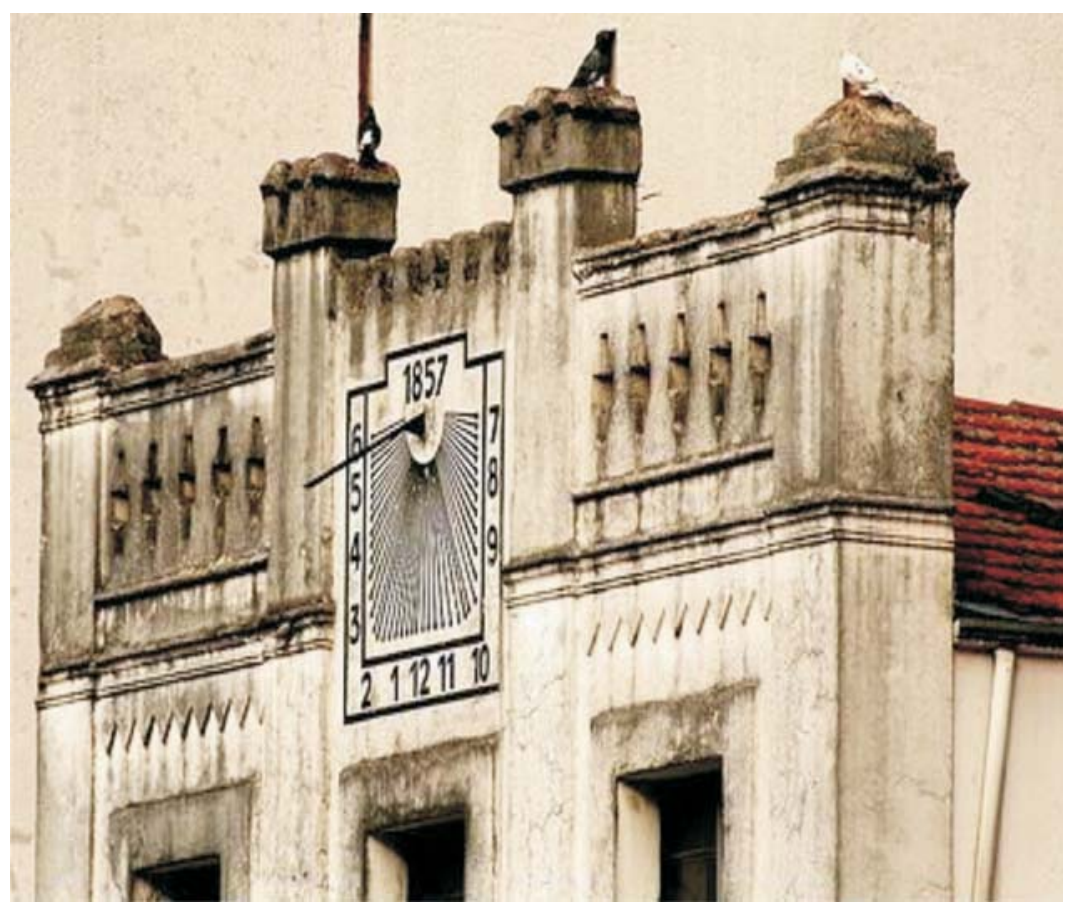

Fonte: Domínio Público.

Relógio existente na fachada da farmácia existente na Praça Tiradentes, defronte à catedral metropolitana de Curitiba. 


\section{Fundamentação}

Apresenta-se aqui, de forma simplificada, fundamentos astronômicos e, posteriormente, fundamentos didáticos para o relógio solar proposto. Trata-se de um relógio construído, todo ele, mediante pintura feita no solo. O tradicional gnomon sólido é substituído pelo próprio observador, adequadamente posicionado em relação a sua estatura (conforme explicação abaixo).

\section{Astronomia}

As horas decorrem principalmente de dois movimentos aparentes da Terra em relação ao sol: translação ao longo do plano da eclíptica e rotação ao redor do próprio eixo.

Se o ciclo de um dia tem 24 h, então cada hora corresponde à rotação de $15^{\circ}$ da Terra ao redor do próprio eixo. Este movimento é percebido, da superfície da Terra, como uma translação do sol ao redor da Terra.

No entanto, neste movimento aparente, o sol quando nasce sobe, e depois desce sobre um plano inclinado em relação ao horizonte. Esta inclinação é igual à latitude do local. No Equador, excepcionalmente, o sol sobe e depois desce sobre um plano vertical. Nos pólos Sul e Norte, o sol se movimenta paralelo ao horizonte.

Há ainda um fato interveniente, que é a inclinação de $23^{\circ} 25^{\prime}$ do eixo da Terra em relação ao referido plano. $\mathrm{O}$ efeito disto, percebido sobre a superfície da Terra, é de o plano seguido no movimento aparente do sol se deslocar gradativamente ao longo do ano, ora mais para Norte (junho), ora mais para Sul (dezembro). Num local sob o Equador, este deslocamento é tal que o nascente se movimenta mais ou menos $23^{\circ} 25^{\prime}$ para o Norte, ou para o Sul em relação a Leste. Ao se afastar do Equador, este des- locamento aumenta progressivamente. Em território brasileiro, isto se dá mais acentuadamente ao se caminhar em direção ao extremo Sul, mas o deslocamento não ultrapassa mais ou menos $28^{\circ}$. Um caso extremo já ocorre sobre o Círculo Polar Ártico: ali, o sol nasce exatamente no pólo de mesmo nome do hemisfério (neste caso, o Sul) no solstício de verão (único dia de 24h), e nasce exatamente no pólo de nome oposto ao hemisfério (neste caso, o Norte) no solstício de inverno (única noite de 24h). Já para além do Círculo Polar, no inverno tem-se não mais somente um dia, mas todo um período em que a noite tem $24 \mathrm{~h}$; e no verão, um período em que o dia tem $24 \mathrm{~h}$. Este período tem por centro os solstícios (sempre mais comprido ao se caminhar em direção ao pólo, até atingir seis meses no Pólo).

Tudo o que foi dito para o hemisfério Sul se repete no hemisfério Norte, apenas considerando que quando um hemisfério tem seu verão, o outro tem seu inverno e vice-versa.

\section{O relógio solar plano}

Considere-se, por exemplo, a cidade de Curitiba, com latitude aproximada de $25^{\circ}$ Sul. O procedimento que será descrito pode ser repetido numa outra cidade, com algumas adaptações do tipo de relógio (pois há tipos mais ou menos oportunos de acordo com a faixa de latitude).

Uma barra alongada em relação ao solo, alinhada em orientação paralela ao eixo da Terra, terá a propriedade de projetar sombras, a cada hora, sobre linhas que permanecerão imóveis a despeito da estação do ano. $\mathrm{O}$ que poderia mudar seria a posição exata da sombra sobre estas linhas: a sombra se deslocaria, no inverno mais para o Sul, e no verão mais para o Norte. Esta é a marcação que dá origem ao relógio solar e que permite, inclusive, a leitura das estações. 


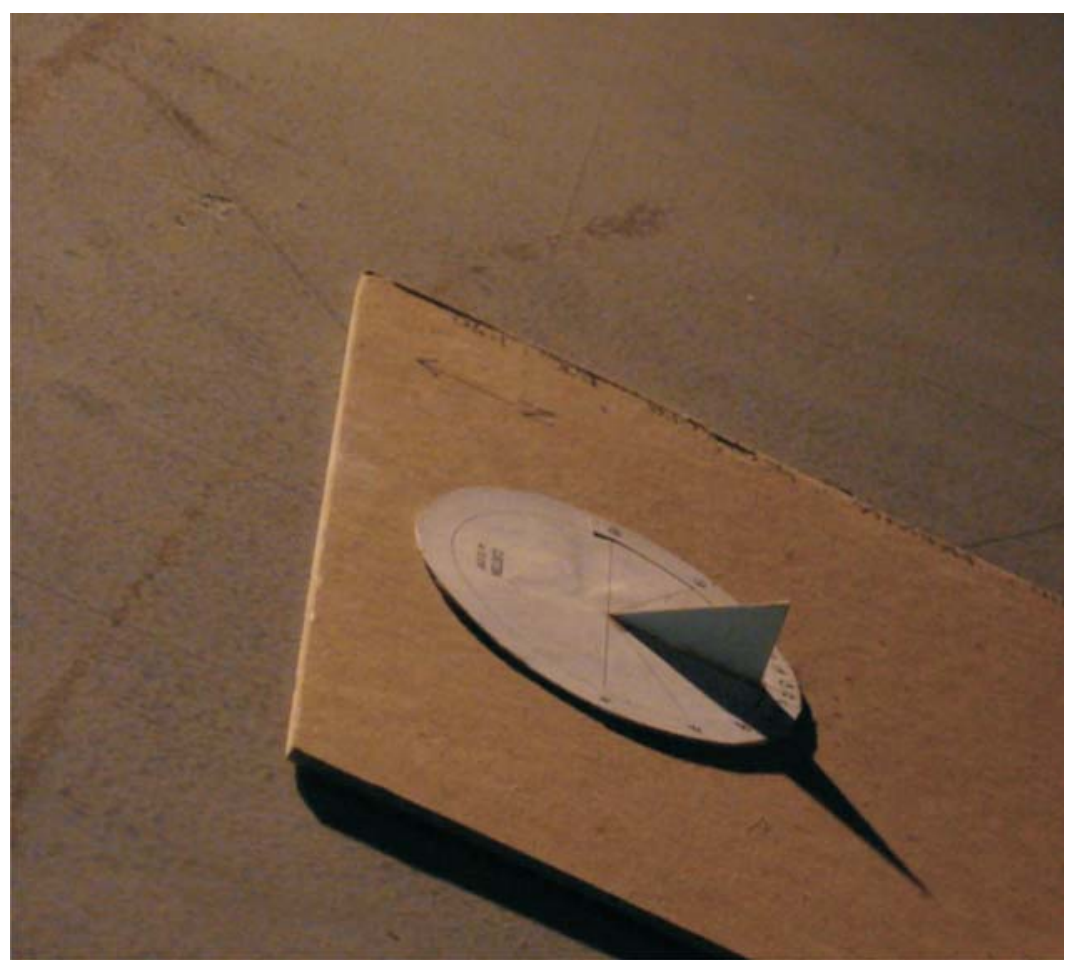

Fonte: Laboratório de conforto ambiental, UFPR.

Como o chão é inclinado da latitude do local, a linha superior do gnomon é perpendicular ao plano do movimento aparente do sol.

Uma representação deste modelo de relógio solar, baseado na construção de um gnomon sobre um pátio plano e livre de sombras, é mostrada na Fonte: Laboratório de conforto ambiental, UFPR.

Como o chão é inclinado da latitude do local, a linha superior do gnomon é perpendicular ao plano do movimento aparente do sol.. A fotografia foi obtida no simulador de trajetória solar, no Laboratório do Ambiente Construído (UFPR), em que este relógio solar foi testado.

Inicialmente, imagine-se que ainda uma pessoa entra debaixo da barra e ajusta sua posição, corretamente na vertical, de modo que a cabeça toque a barra. Pois a sombra de sua cabeça estará, a todo momento, tangenciando a linha de hora correspondente. Qualquer pessoa, independendo de sua altura, poderá ler as horas assim.

Se for feita no solo uma marcação que permita cada pessoa encontrar o ponto em que, com sua estatura, encontraria com a cabeça a barra, então a barra poderia ser eliminada. $\mathrm{O}$ relógio solar se reduz a uma série de linhas e marcações no chão. É esta a novidade deste trabalho: ao invés de uma barra engastada no solo, a barra seja construída de forma virtual com a estatura das pessoas que forem ler o relógio. Tal design apresenta três vantagens:

- econômico: gasta-se apenas tintas;

- segurança: deixa-se de construir um objeto potencial causador de acidentes como contusões no ambiente escolar;

- interativa: as crianças da escola, e mesmo adultos, terão de participar com seu corpo se quiserem ler as horas; assim, estarão mais conscientes da orientação solar.

Além da marcação de uma escala de alturas sobre o solo é importante que se marque numa parede próxima uma escala de alturas, para que as pessoas inicialmente possam ler sua altura, para depois ocuparem sua posição na 
sua escala deformada do relógio. É uma escala deformada, pois a distância entre dois pontos para pessoas de estaturas distintas não necessariamente corresponderá à diferença real entre as estaturas.

\section{Determinação do Norte verdadeiro}

Mediante o uso de bússolas é possível encontrar-se o Norte magnético (embora aqui seja possível uma atividade extra de construção de uma bússola rudimentar, é conveniente utilizar-se uma bússola profissional).

Como o núcleo magnético da Terra é móvel, é necessário o uso de um valor de referência da declinação magnética (mapeado por localidade, em curvas isogônicas, obtémse para Curitiba, na data de referência 01/01/ 1990, o valor de $-16^{\circ}$ ) e ainda um valor para a variação anual na localidade, (mapeado em curvas isopóricas, obtém-se para Curitiba -7,6 minutos/ano), sendo este multiplicado pelo tempo decorrido desde a data de referência do mapa e a data em questão (17,3 anos em abril de 2007).

Logo, tem-se

$=-16,0-7,6 \times 17,3=16^{\circ}-131,5$ minutos $=-18,2^{\circ}$

Sendo a declinação de valor negativo, o Norte verdadeiro está a $18,2^{\circ}$ a partir do Norte magnético, contados no sentido horário.

\section{Traçado do gabarito}

O gabarito para o traçado do relógio solar é obtido da projeção, sobre o chão, da sombra que teria a cada hora uma barra mantida paralela ao eixo da Terra (orientada para o Norte e inclinada para o chão, no ângulo da latitude). Considera-se cada hora do dia (Figura 3).

Cada hora gera um ponto sobre o solo. Cada um destes é então unido ao ponto em que o eixo da Terra intercepta o solo, chamado centro do relógio (Figura 4Fonte: os autores. Etapa posterior de construção do relógio solar. ).
FIGURA 3 -A DIREÇÃO DE CADA HORA PROJETADA SOBRE O CHÃO.

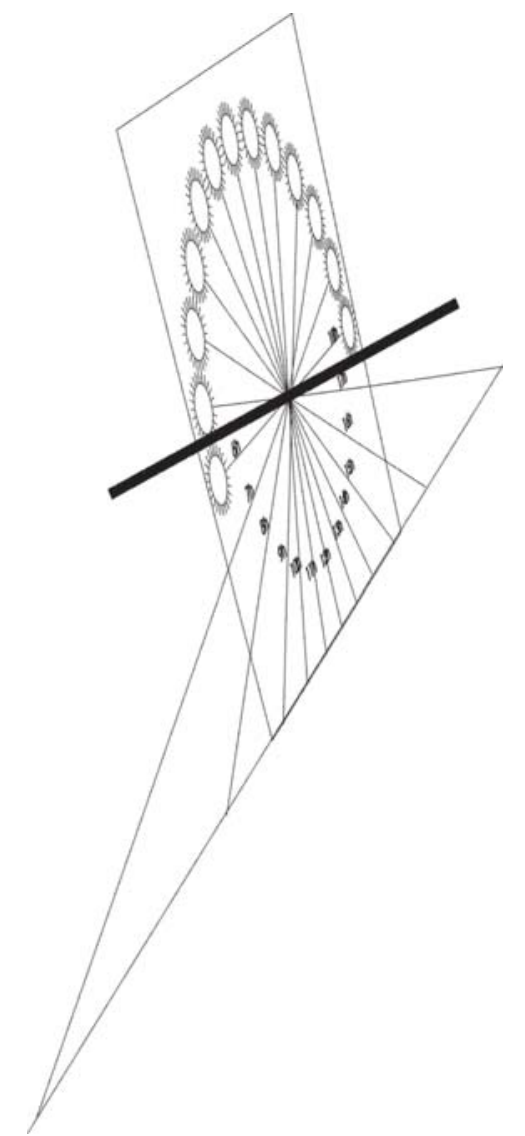

Fonte: os autores.

Etapa inicial da construção do relógio solar.

A partir do centro do relógio, é construída, na direção Norte-Sul e no sentido Sul, uma escala deformada de estaturas em que cada acréscimo unitário de estatura corresponde, no solo, a 1 / tg (latitude). Obtémse assim o gabarito para traçado do relógio solar (Figura 5).

Os ângulos de azimute e altura solar para cada hora, obtidos da literatura (por exemplo, FROTA, 2004) para cada mês ou estação do ano, permitem ainda determinar, sobre o gabarito, a sombra de um objeto de altura prédefinida. Unindo-se as extremidades destas sombras para cada hora, obtêm-se a curva de sombra para cada mês ou estação do ano. Estas linhas não são fundamentais para a leitura das horas; no entanto, acrescentam importante conteúdo ao relógio. 
FIGURA 4 - LINHAS DAS SOMBRAS DO EIXO DA TERRA SOBRE O CHÃO

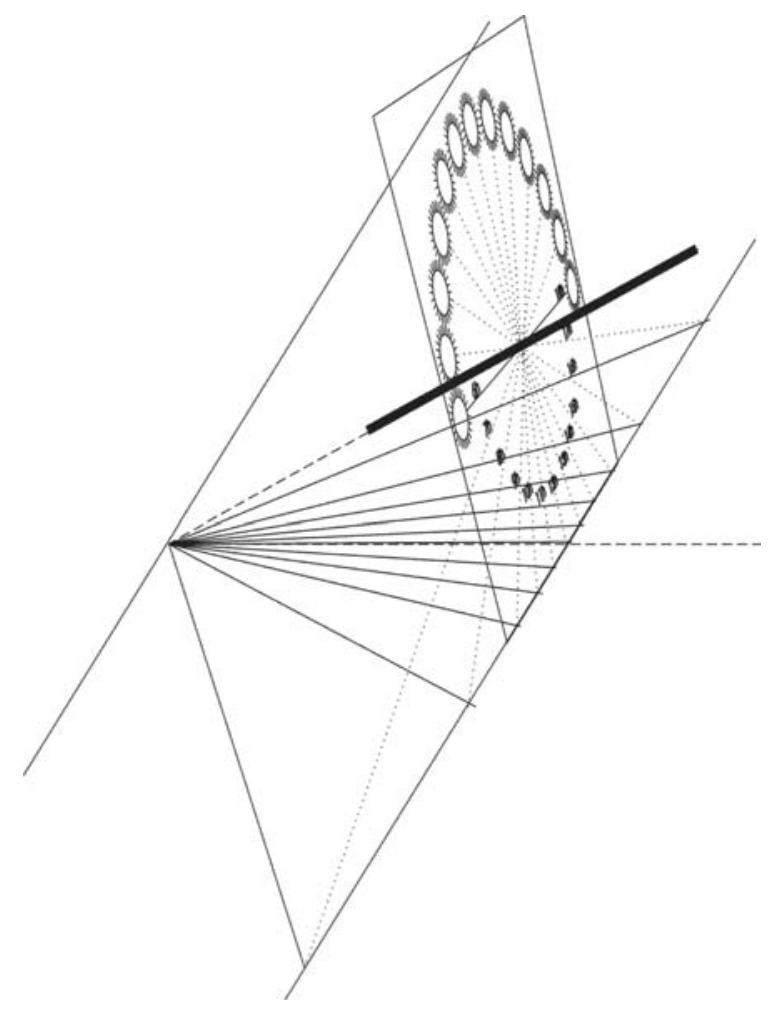

Fonte: os autores. Etapa posterior de construção do relógio solar.

FIGURA 5 - GABARITO

\section{GABARITO PARA CONSTRUÇÃO DE RELÓGIO SOLAR PARA A CIDADE DE CURITIBA $\left(25,5^{\circ} \mathrm{S}\right)$}

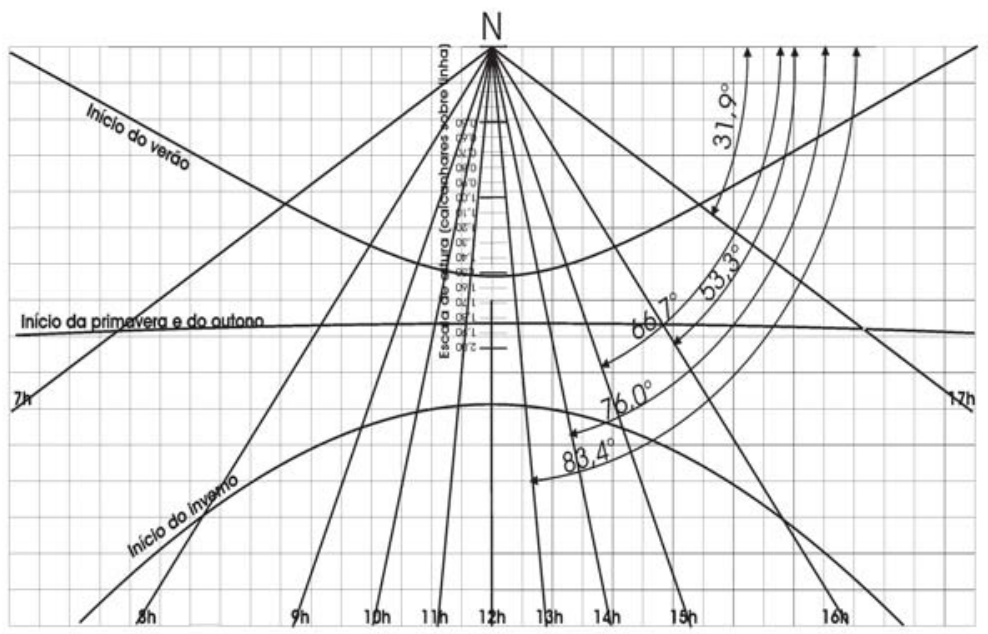

Inhas de estaçbes somente válidas para individuos de alura $=1,5 \mathrm{~m} \quad$ Esc: 1 quadrado $=0,5 \mathrm{~m} \times 0,5 \mathrm{~m} \quad$ Abisis $\mathrm{L}$. Schmid $\quad$ 15/4/2007

Fonte: os autores 
O relógio solar descrito acima, adequado para a cidade de Curitiba (considerando a latitude), pode ser adaptado a regiões cuja latitude não exceda a faixa entre $10^{\circ}$ e $45^{\circ}$ ao Sul (ou ao Norte). Torna-se inviável numa localidade mais próxima do Equador: a escala deformada de alturas se torna demasiadamente longa.

Exatamente sob o Equador, as linhas horárias seriam todas paralelas, e seria necessário um conjunto de linhas para cada estatu- ra. Neste caso, torna-se conveniente o relógio construído com um cilindro fixo, sendo as linhas referidas à sua altura. Há ainda outros modelos cujo marcador é feito em formas tridimensionais, como o segmento de calha cilíndrica voltado para cima, assemelhando-se a uma pista de skate; ou um relógio cuja leitura é obtida a partir do reflexo de uma moeda que reflete a radiação solar sobre o mostrador em calha voltada para baixo (Figura 6).

FIGURA 6 - RELÓGIO SOLAR EM MEDELIN (COLÔMBIA).

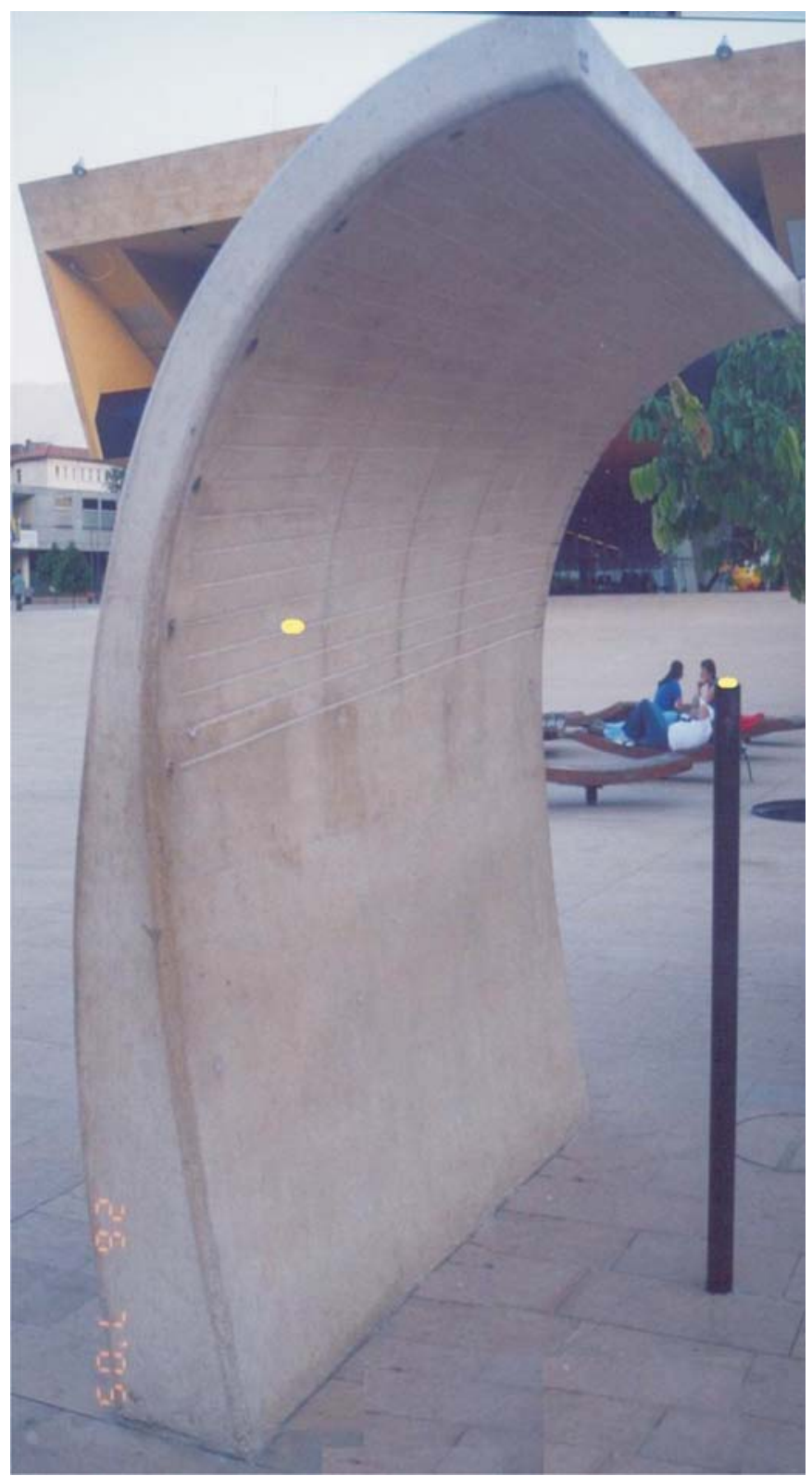

Fonte: Aloísio l. Schmid. Relógio solar em calha invertida. 
Já em latitudes altas (a partir de $45^{\circ}$ ), a escala deformada de alturas se comprime. Isto dificulta a precisão, sendo mais aconselhável uma barra fixa.

Do ponto de vista da didática, o relógio solar em modalidade interativa, em que o próprio corpo com sua estatura faz parte da leitura das horas, convida à observação sistemática da natureza, que se insere naturalmente no ciclo de um ano inteiro, e continua nos outros anos se diferenciando, uma vez que, ao crescer, as crianças são convidadas a continuar lendo. Além disso, abre espaço para o desenvolvimento de conteúdos diversos no âmbito da aprendizagem, envolvendo disciplinas diversas como Matemática, Ciências e Artes por exemplo.

\section{Materiais e métodos}

\section{Implementação do relógio}

O procedimento de implementação do relógio compreende os seguintes passos:

1)localizar aproximadamente o Norte

2) encontrar uma área perfeitamente plana de aproximadamente $16 \mathrm{~m}$ (Leste-Oeste) por $8 \mathrm{~m}$ (Norte-Sul), distante de objetos altos como árvores, construções ou muros que possam lhe projetar sombras;

3) determinar o Norte com bússola e acrescentar-lhe a correção devida à declinação magnética (que era de $18,2^{\circ}$ para Curitiba em abril de 2007, mas deve ser atualizada para cada local); 4) traçar um eixo Norte-Sul no meio da área selecionada;

5) traçar, perpendicular a este, um eixo Leste-

Oeste na porção mais ao Norte da área selecionada;

6) traçar o restante do retângulo de $16 \mathrm{~m} \times 8 \mathrm{~m}$, ou dimensões menores, caso haja restrição de espaço;
7) sobre o gabarito, fazendo coincidir a linha Leste-Oeste mais ao Norte e a linha Norte-Sul central, reproduzir o retângulo assim determinado, observando a escala do desenho;

8) de cada uma das linhas horárias, sobre o retângulo assim obtido no gabarito, a partir dos catetos, reproduzir sobre o solo a extremidade de cada linha, a ser unida com o ponto central a Norte;

9) para cada uma das linhas horárias, esticar um barbante desde o centro até a extremidade e, depois de eliminar resíduos de poeira na região ao longo do barbante, com um rolo e tinta traçar a linha horária correspondente;

10) depois de feitas estas linhas, mediante uso do quadriculado e escala, reproduzir as linhas de estação do ano;

11) escrever números das horas;

12) a partir do centro da linha Leste-Oeste mais a Norte, marcar a escala de alturas deformada: cada $10 \mathrm{~cm}$ no chão correspondem a $10 /$ tg (latitude) (em cm);

13) escrever números da altura na escala deformada - linha correspondente às $12 \mathrm{~h}$;

14) construir sobre uma parede próxima uma régua de estatura na escala $1: 1$;

15) os executores tem total liberdade para trabalhar o layout do relógio.

\section{Modo de leitura}

O relógio construído a partir do gabarito aqui apresentado marca, para cada localidade, a hora local. Isto significa que a hora oficial pode estar adiantada ou atrasada, a depender da longitude. A hora oficial do Brasil (Brasília) é baseada no fuso horário de $45^{\circ}$ Oeste. Já a cidade de Curitiba se encontra a $49,25^{\circ}$ a Oeste.

Cada fuso horário tem $15^{\circ}$, ou seja, cada $1^{\circ}$ de longitude equivale a uma diferença de 4 minutos no horário. A diferença de $-4,25^{\circ}$ equivale, portanto, a $(4,25 \times 4)=17$ minutos. Assim, em Curitiba, o Sol estará na "posição de meio-dia" às $12 \mathrm{~h} 17 \mathrm{~min}$. Um relógio solar que 
assimilasse na sua marcação esta defasagem deveria seguir um outro gabarito, já não mais simétricas em relação à linha Norte-Sul central. Entretanto, considera-se instrutivo que o relógio marque o tempo local, para que se tenha consciência do caráter de convenção que tem o horário oficial.

\section{Discuss dos resultados}

Mediante entendimento preliminar com a Secretaria Municipal de Educação do Município de Curitiba, no período entre 27/4/2007 e 4/5/2007, foram construídos relógios solares em nove escolas, uma em cada um dos núcleos em que estão organizadas as 181 escolas do município. Cada escola foi atendida por um grupo de quatro ou cinco alunos do segundo ano do Curso de Arquitetura e Urbanismo, e mais um orientador em tempo parcial, escolhido entre a equipe da disciplina: além do professor, duas mestrandas (em seu estágio de docência), a monitora da disciplina e uma bolsista de inicia- ção científica. Os estudantes de arquitetura receberam previamente instruções teóricas e práticas a respeito da orientação solar, ao longo de três aulas de três horas.

Nas duas semanas prévias à realização das pinturas, as escolas foram visitadas pelas equipes para avaliação das condições. Em dois casos foi necessária a substituição das escolas, por constatação da ausência de espaço adequado ao tipo de relógio solar em pauta. Uma solução possível, mas nem sempre aceita pelas escolas é a realização da pintura sobre as quadras poli-esportivas. Em tais situações, optou-se por linhas tracejadas e cores discretas como o azul marinho ou marrom.

A pintura de cada relógio solar levou entre seis e nove horas: ou seja, um dia de trabalho. Mostrou-se importante a realização da pintura num dia ensolarado, tanto pela rapidez de secagem assim obtida, como pela possibilidade de testar o relógio durante a marcação. No entanto, a atividade se mostrou árdua com respeito à radiação solar, recomendando-se cuidados com a ingestão de bebidas e proteção adequada da cabeça e da pele contra os raios solares.

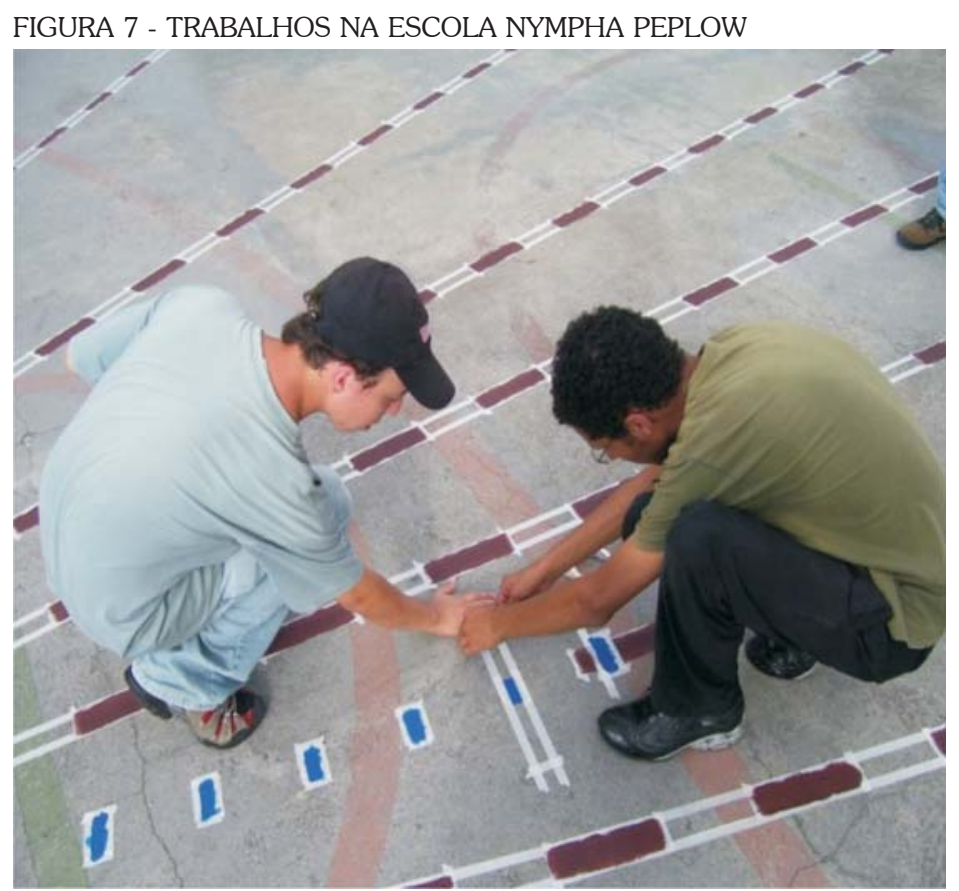

Fonte: Laboratório de conforto ambiental (UFPR) 
No caso de erro na pintura sobre piso de cimento, é possível corrigi-la logo após a secagem atritando-se sobre tal trecho um pedaço de bloco de concreto, que desempenha o papel de borracha.

Duas semanas após a realização das pinturas, foi convocada uma reunião com um representante de cada escola municipal de Curitiba, em que a experiência foi relatada pela equipe da UFPR. Em tal ocasião, os professores das escolas que não receberam os relógios solares manifestaram o interesse em receber instrução para também construírem os seus. Já os professores das escolas selecionadas para realização dos nove relógios solares apresentaram críticas quanto à falta de esclarecimento das equipes de professores sobre a maneira de utilização dos relógios, e seu princípio de funcionamento, de modo a poderem responder perguntas dos alunos. Ainda, foram levantadas preocupações quanto à inserção desta atividade no contexto de diferentes disciplinas: Ciências, Matemática e Artes. Constatou-se, em tal ocasião, a necessidade da realização de um seminário com professores, envolvendo o preparo de um material impresso de apoio.

\section{FIGURA 8 - TESTE DO RELÓGIO NA ESCOLA EVA DA SILVA}

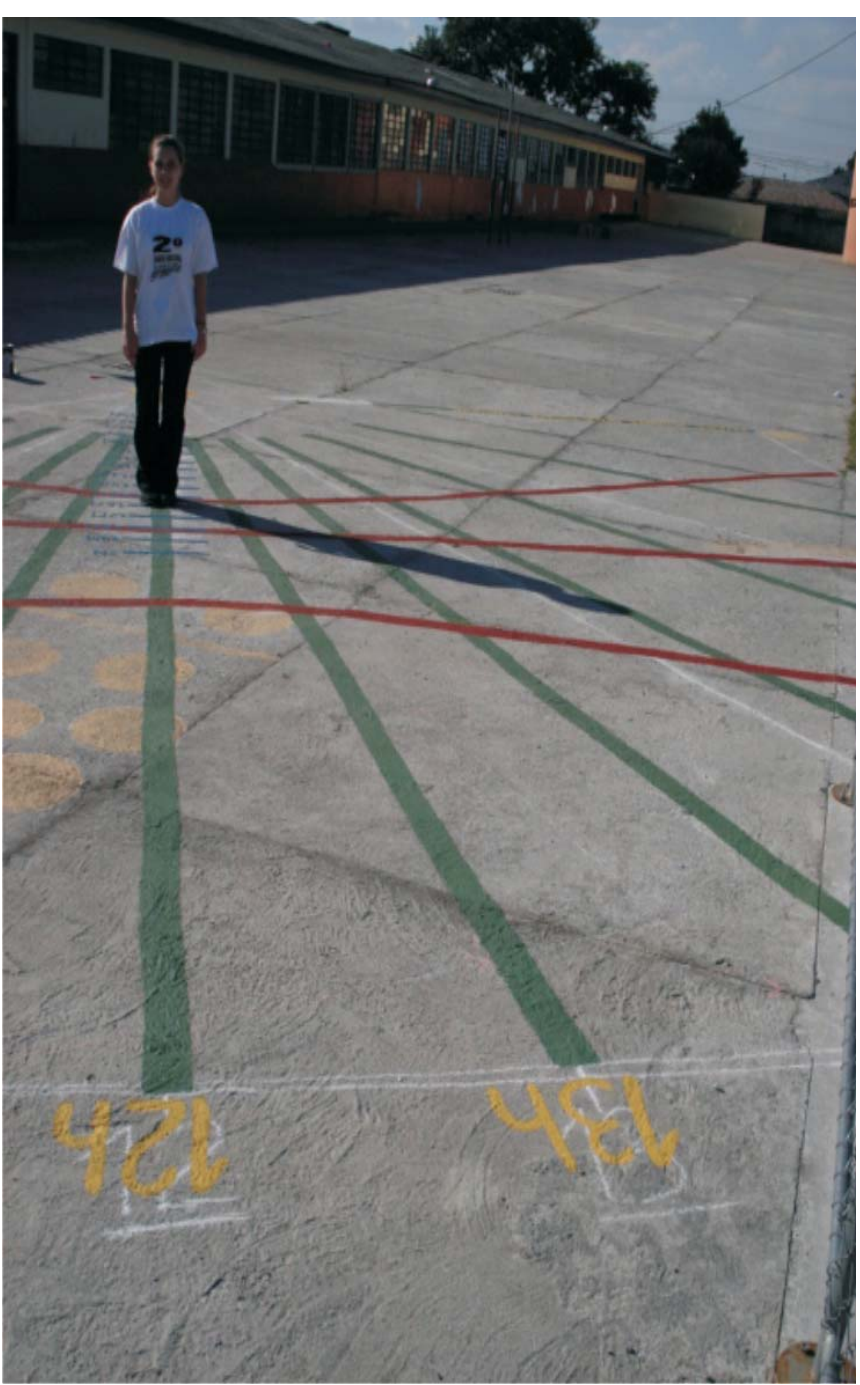

Fonte: os autores.

Esta foto demonstrou que o erro na leitura é menor que 5 minutos. 


\section{Agradecimentos}

Ao cartógrafo Roberto Teixeira Luz pelos cálculos e esclarecimentos referentes à declinação magnética e hora civil. À Secretaria

\section{REFERÊNCIAS}

FROTA, A. B. Geometria da insolação. São Paulo: Geros, 2004
Municipal de Educação pelo apoio à iniciativa. À monitora da disciplina Conforto Ambiental I, Mônica Máximo da Silva, e à bolsista de Iniciação Científica Claudia Morishita pela orientação de equipes durante a realização dos relógios.

LUZ, R.T. Correção da direção do Norte magnético para utilização com tabelas solares (Norte verdadeiro). Comunicação pessoal. Curitiba, 2007.

Texto recebido em 19 mar. 2008.

Texto aprovado em 24 jun. 2008. 